\title{
NUMERICAL MODEL AND EXPERIMENTAL TESTS FOR DC TO DC BOOST CONVERTER
}

\author{
CORCAU, J. I. \& DINCA, L.
}

Abstract: This chapter presents a simulation model and experimental tests for a DC to $D C$ boost converter. The simulation model was accomplished in MULTISIM 12, the $P C B$ was designed using OrCAD Layout and data acquisition for experimental tests was performed using LabView. The experimental model amplifies the 24 VDC input to 48 VDC output, with a maximum power of $500 \mathrm{~W}$. This converter can be used both in laboratory, for didactical and research purposes, but also, with adaptations and improvements in the aero-spatial domain, on satellites, especially. In these cases it is integrated in energetic systems by the side of fuel cells, hydrogen and oxygen regeneration systems or photovoltaic cells. The implemented control is a P.I. one, with discrete components, so the scheme is useful in didactical purposes at laboratory sessions. The command is a classic PWM with a switching frequency of $10 \mathrm{kHz}$. The converter is provided with over-voltage and over-current protection and contains also measurement schemes for the input and output voltages and currents. These signals are acquired with a data acquisition card and processed in LabView and MATLAB.

Key words: DC to DC boost converter, control P.I, PWM, modeling in MULTISIM, ORCAD
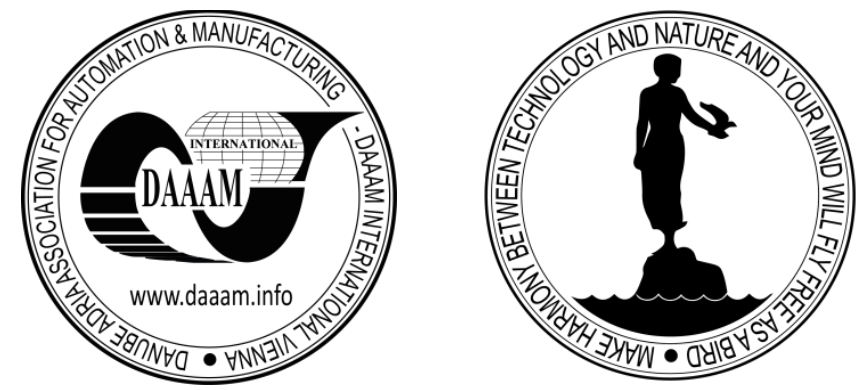

Authors' data: Senior Lecturer PhD. Corcau, J[enica] Ileana, Associate Professor PhD. Dinca, L[iviu], University of Craiova, Decebal, 107, Romania, jcorcau@elth.ucv.ro; ldinca@elth.ucv.ro

This Publication has to be referred as: Corcau, J[enica Ileana] \& Dinca, L[iviu] (2015). Numerical Model and Experimental Tests for DC to DC Boost Converter, Chapter 07 in DAAAM International Scientific Book 2015, pp.067-086, B. Katalinic (Ed.), Published by DAAAM International, ISBN 978-3-902734-05-1, ISSN 17269687, Vienna, Austria

DOI: $10.2507 /$ daaam.scibook.2015.07 


\section{Introduction}

DC to DC power converters serve to transform the input electrical energy with some parameters in output energy with different parameters. The input voltage for DC to DC converters is not stabilized but the output voltage is stabilized due to the control system of the converter. These converters are known as "choppers" in literature, circuit elements having a small dissipated power (Rashid M, 2003), (Chellappan M.V , 2008), (Marsala G, 2008), (Fadali H, 2008), (Misoc F, 2007), (Biswal M et al., 2012), (Sathya P et al., 2013), (Kabalo M et al., 2012), (Sangswang A et al., 2004), (Johansson B., 2004).

The boost converter circuit is presented in figure 1. The main components are: the switch (a MOSFET), a diode, one coil and one capacitor. Its functioning is coordinated by a PWM controller. The scheme designed in this paper contains auxiliary protection and signal conditioning blocks. The latter serve to acquire the internal parameters of the converter, useful in didactical and research process. These converters are widely used in aeronautic and spatial domain, an important application being on MEA (More Electrical Aircraft).

In (Sathya P et. al., 2013) one study a boost converter for photovoltaic systems, which amplifies the input $12 \mathrm{~V}$ voltage to $24 \mathrm{~V}$ output voltage, using a switching frequency of $219 \mathrm{kHz}$. Are presented the theoretical model, the MULTISIM model and the experimental converter. It is used a simple command scheme using a differential amplifier which command a 555 oscillator. The switching element is a MOSFET. In (Sangswang A et al., 2004) is presented a study concerning the noise generated by a boost converter, also with MOSFET, but commanded by specialized integrated circuits. There are shown stochastic models and experimental results for the boost converter. In (Bizon N et al., 2006) research the stability of a boost converter provided with a non-linear fuzzy controller. The converter is also with MOSFET, with a maximum power of $900 \mathrm{~W}$. Another solution for the boost converter is proposed in (Kabalo M et al., 2012). It uses interleaved phases control in order to reduce the input current ripples. In this case the switches are IGBTs and is designed to work with fuel cell stacks which can't sustain high amplitude and high frequency ripples. A high power $(10 \mathrm{~kW})$ boost converter is presented in (Liu J., et al., 2010). There is used again the interleaved phases technique. The switch is a SiC MOSFET. A small power boost converter is designed in (Hemachander P et al., 2011). The converter is coordinated by a microcontroller, which simplify the entire scheme and the switch in a MOSFET. There are presented numerical simulations and experimental results. A buck converter is developed in (Johansson B. 2004). There are used also MOSFET switches, the conversion is realized between $24 \mathrm{~V}$ and $12 \mathrm{~V}$ and the loads are between 2 and $6 \Omega$. A buck converter used to emulate the functioning of a fuel cell is studied and realized in (Marsala G, 2008). Are used IGBT switches and the command and control are implemented with a microcontroller, so the output characteristics emulate as well as possible the fuel cell characteristics. The output power is about $600 \mathrm{~W}$.

In this chapter is realized a boost converter with MOSFET switches, the switching frequency is $10 \mathrm{kHz}$, input voltage is $24 \mathrm{VDC}$ and the output voltage is $48 \mathrm{VDC}$. One follows to obtain a maximum power about $500 \mathrm{~W}$. There are presented theoretical 
aspects, converter model in MULTISIM 12, the implementation of the converter and also the numerical and experimental results. The classical scheme of the boost converter is shown in figure 1 (Priambodo P., et al., 2013), (Dinca L., et al., 2013).

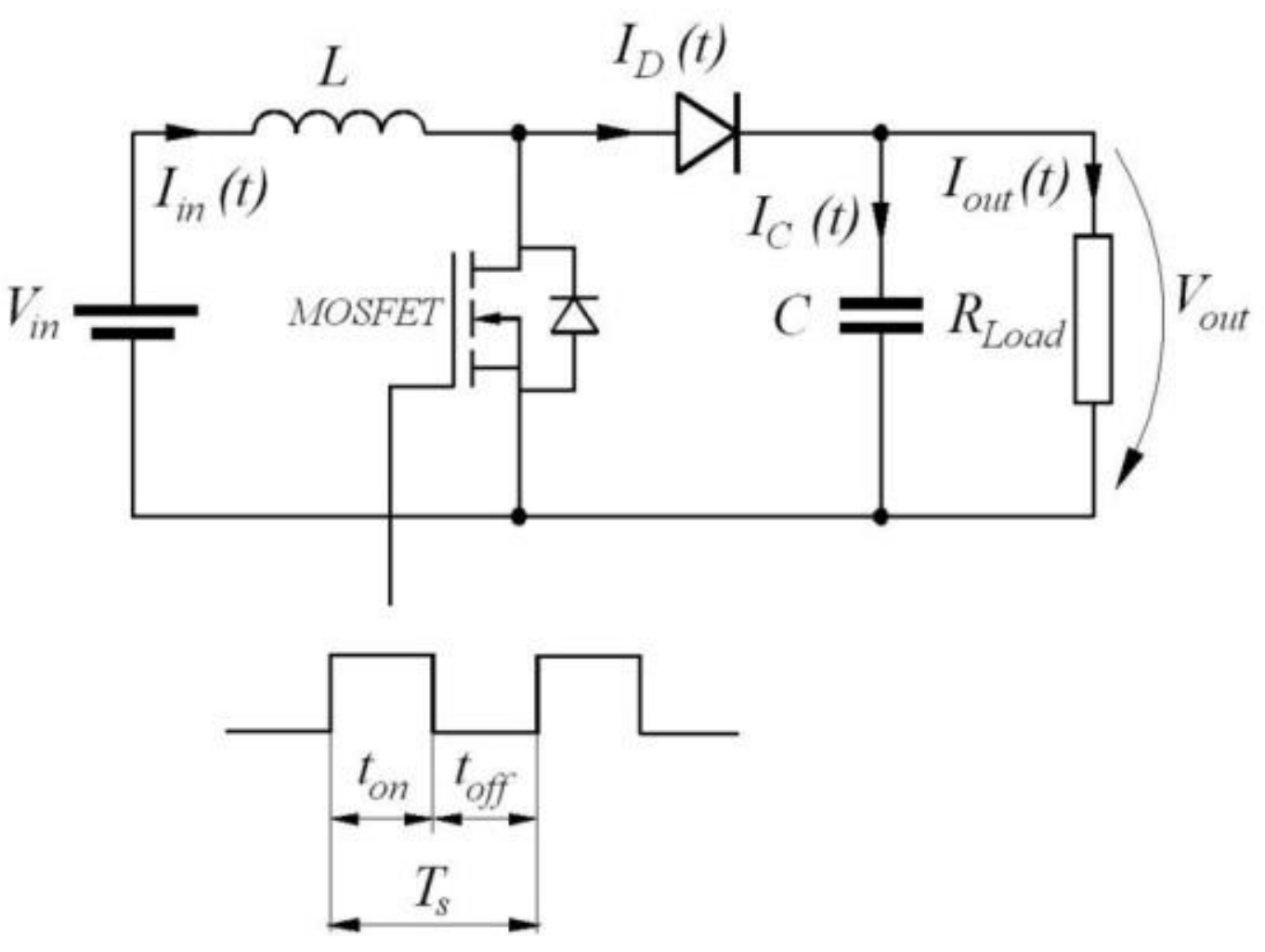

Fig. 1. Principle scheme of the boost converter

The converter circuit is used in two modes, which depends on the energy storage capacities and the relative length of commutation period. These modes are known in literature as CCM (Continuous Conduction Mode) and DCM (Discontinuous Conduction Mode). The CCM is the efficient conversion mode and the DCM is the low conversion mode.

\section{CCM mode}

Case $1\left(0<t \leq t_{\text {on }}\right)$ starts when the switch passes to "ON" at $t=0$ and ends when the switch pass to "OFF" at $t=t_{o n}$. The equivalent circuit for this mode is described by figure 2b. Supposing the internal resistance of the source is small and the coil current positive and increases linearly, the coil voltage is equal with the input voltage.

Case $2\left(t_{o n}<t \leq T_{s}\right)$ starts when the switch passes to "OFF" and ends when it passes again to "ON" at $t=T_{s}$. The equivalent circuit in described by figure $2 \mathrm{c}$. The coil voltage in this case is the difference between the output and the input voltages. In this case $V_{\text {in }}<V_{\text {out }}$. The steady state is characterized by the signal determined by these periodical commutations, at constant input voltage and constant output load. 


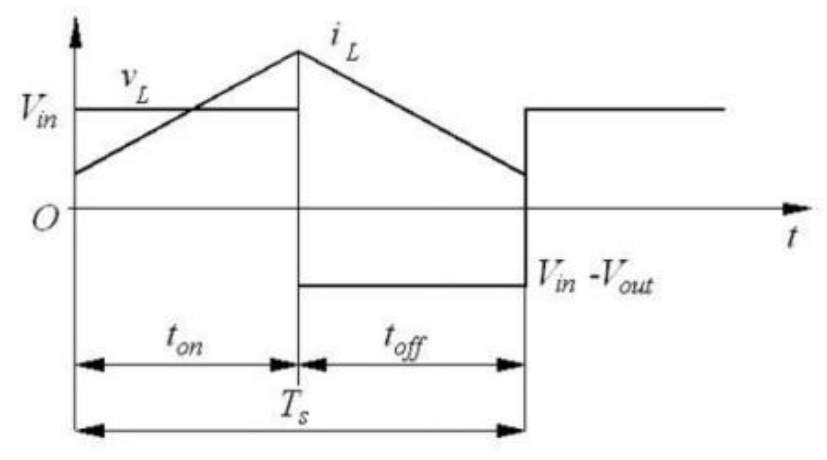

a

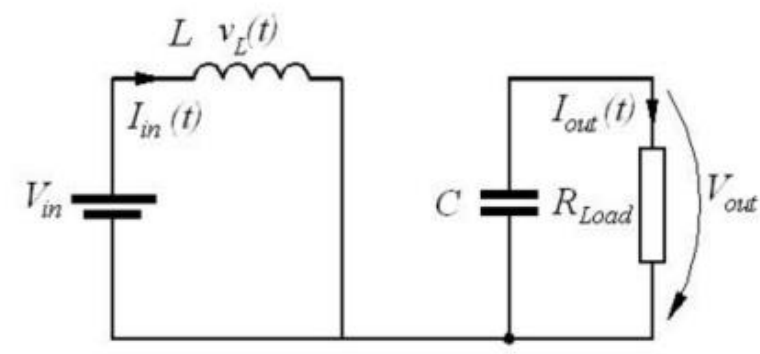

b

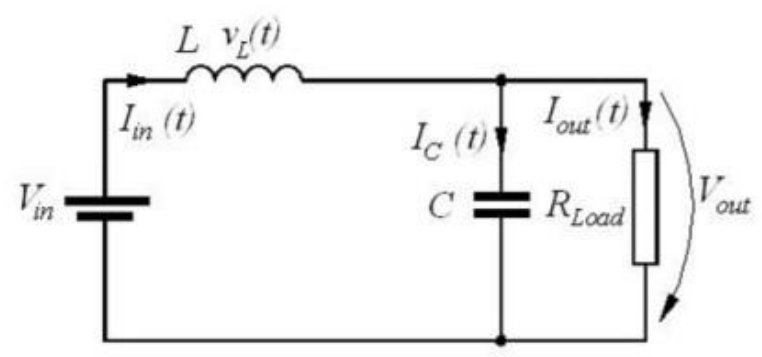

c

Fig. 2. CCM mode. a - waveforms; b-switch "ON", c-switch "OFF" (Priambodo P., et al., 2013)

In stationary regime, because there are no energy accumulations in the circuit, the integral of the coil voltage $V_{L}$ over one period $T_{s}=t_{o n}+t_{\text {off }}$ is null. So, the total weighted sum of the coil voltages when the switch is "ON" and the switch is "OFF" has to be zero (Priambodo P., et al., 2013), (Rashid M, 2003), (Sangswang A et al., 2004),

$$
V_{\text {in }} t_{\text {on }}+\left(V_{\text {in }}-V_{\text {out }}\right) t_{\text {off }}=0
$$

where $V_{\text {in }}$ - is the input voltage, $V_{\text {out }}$ - medium output voltage, and $t_{\text {on }}, t_{\text {off }}$ and $T_{s}$ are presented in figure 2.

From (1) results

$$
\frac{V_{\text {out }}}{V_{\text {in }}}=\frac{T_{s}}{t_{\text {off }}}=\frac{1}{1-D}
$$

where $D$ is the duty cycle.

The duty cycle is between 0 and 1 and one observe the output voltage is higher the input voltage. Relation (2) represents the control characteristic of the boost converter.

Considering the boost converter as ideal, $P_{\text {in }}=P_{\text {out }}$, so

$$
V_{\text {in }} I_{\text {in }}=V_{\text {out }} I_{\text {out }},
$$


And one obtain

$$
\frac{I_{\text {out }}}{I_{\text {in }}}=\frac{V_{\text {in }}}{V_{\text {out }}}=1-D,
$$

Where $I_{\text {out }}$ is the output average current and $I_{\text {in }}$ is the average input current.

When the switch is "ON", the coil voltage is equal with the input voltage, so (Priambodo P., et al., 2013)

$$
V_{L}=V_{i n} ; \quad L \frac{\mathrm{d} i_{L}}{\mathrm{~d} t}=V_{i n},
$$

or

and from this

$$
\frac{\mathrm{d} i_{L}}{\mathrm{~d} t}=\frac{V_{i n}}{L}
$$

$$
\frac{\mathrm{d} i_{L}}{\mathrm{~d} t}=\frac{\Delta i_{L}}{\Delta t}=\frac{\Delta i_{L}}{D \cdot T} \rightarrow \frac{\mathrm{d} i_{L}}{\mathrm{~d} t}=\frac{V_{\text {in }}}{L} .
$$

obtaining in the final

$$
\Delta i_{L(S-\text { close })}=\frac{V_{i n} D T}{L}
$$

When the switch is "OFF"

$$
V_{L}=V_{\text {in }}-V_{\text {out }} ; \quad L \frac{\mathrm{d} i_{L}}{\mathrm{~d} t}=V_{\text {in }}-V_{\text {out }}
$$

or

$$
\begin{aligned}
\frac{\mathrm{d} i_{L}}{\mathrm{~d} t} & =\frac{V_{\text {in }}-V_{\text {out }}}{L} \\
\frac{\mathrm{d} i_{L}}{\mathrm{~d} t} & =\frac{\Delta i_{L}}{\Delta t}=\frac{\Delta i_{L}}{(1-D) T} \rightarrow \frac{\mathrm{d} i_{L}}{\mathrm{~d} t}=\frac{V_{\text {in }}-V_{\text {out }}}{L}
\end{aligned}
$$

and one obtain

$$
\Delta i_{L(S-\text { open })}=\frac{\left(V_{\text {in }}-V_{\text {out }}\right)(1-D) T}{L}
$$

\section{DCM mode}

In this mode the coil current drops to zero before a switching period accomplishes, like in figure 3. Like in CCM mode, the integral of the coil voltage over one switching period is zero, so the weighted sum (Priambodo P., et al., 2013)

$$
V_{\text {in }} D T_{s}+\left(V_{\text {in }}-V_{\text {out }}\right) D_{1} T_{s}=0 .
$$


So

$$
\frac{\mathrm{V}_{\text {out }}}{V_{\text {in }}}=\frac{D_{1}+D}{D_{1}} \text { and } \frac{\mathrm{I}_{\text {out }}}{I_{\text {in }}}=\frac{D_{1}}{D_{1}+D}
$$

Figure 3 describes the equivalent circuit in DCM and comprises the following cases: case $1\left(0<t \leq t_{o n}\right)$, figure $3 \mathrm{~b}$, case $2\left(t_{o n}<t \leq\left(D+D_{1}\right) T_{s}\right)$, figure $3 \mathrm{c}$, and case 3( $\left.\left(D+D_{1}\right) T_{s}<t \leq T_{s}\right)$, figure $3 \mathrm{~d}$.

The average input current is equal with the coil current

$$
I_{i n}=\frac{V_{i n}}{2 L} D T_{S}\left(D+D_{1}\right)
$$

Replacing (13) in (15) results

$$
I_{\text {out }}=\frac{V_{\text {in }} T_{S}}{2 L} D D_{1}
$$

Using (14) and (16) results the duty cycle

$$
D=\sqrt{\frac{4 V_{\text {out }}}{27 V_{\text {in }}}\left(\frac{V_{\text {out }}}{V_{\text {in }}}-1\right) \frac{I_{\text {out }}}{I_{\text {out,avg, } \max }}}
$$

where $I_{\text {out,avg, } \max }$, is the maximum averaged value of the output current found from

$$
I_{\text {outavg }}=\frac{V_{\text {out }} T_{S}}{2 L} D(1-D)^{2}
$$
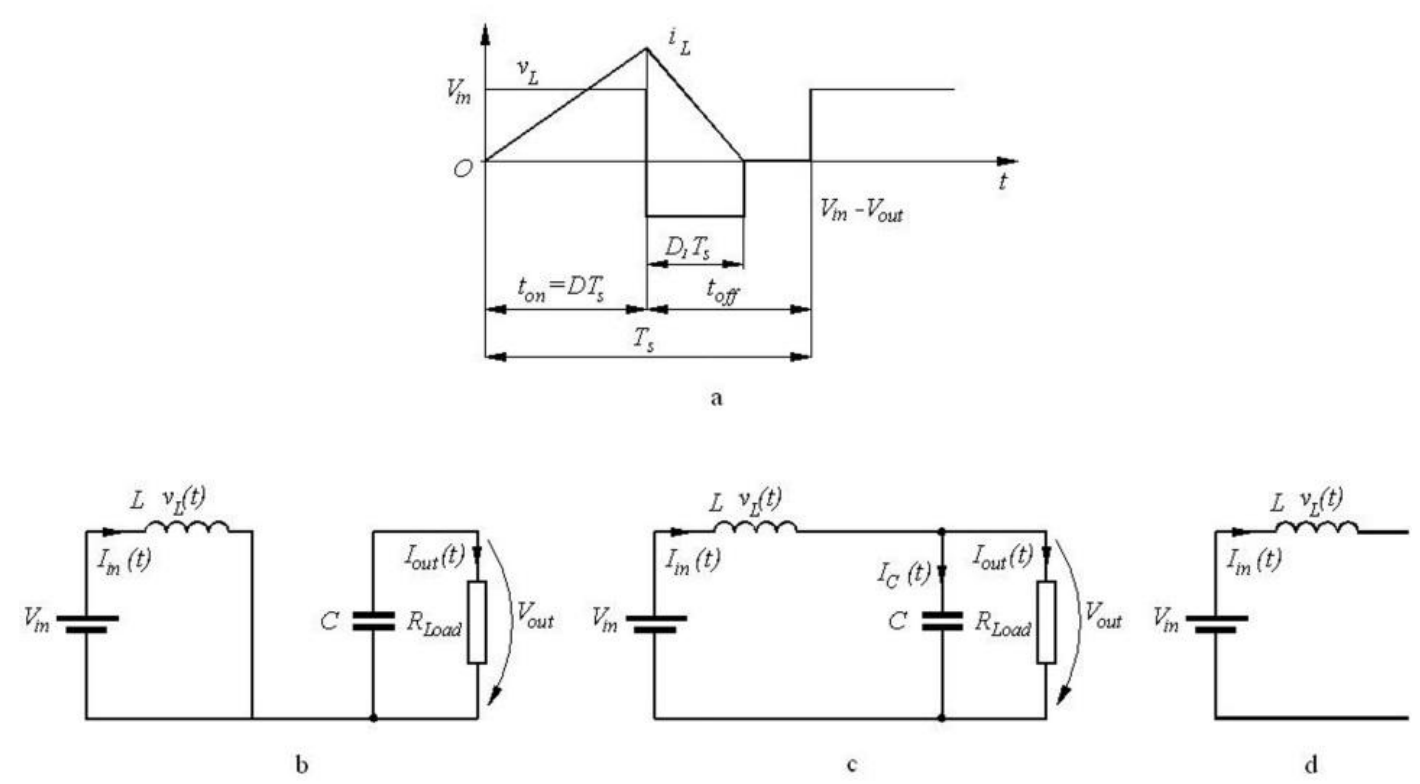

Fig. 3. Equivalent circuit for the DCM mode (Priambodo P., et al., 2013) 
The maximum average value of the input current is reached when $D=1 / 3$

$$
I_{\text {out,avg, } \max }=\frac{2}{27} \cdot \frac{T_{S} V_{\text {out }}}{L}
$$

The critical inductance $L_{b c}$, is defined as the inductance at the boundary between the two modes and may be deduced as (Priambodo P., et al., 2013)

$$
L_{b c}=\frac{R_{\text {load }} D(1-D)^{2}}{2 F_{s}}
$$

Where $R_{\text {load }}$ is the load resistance and $F_{S}$ is the switching frequency.

\section{The converter scheme in MULTISIM}

Converter scheme implemented in MULTISIM is presented in figure 4. Converter basic elements are the coil L1, capacitor C1, diode D3, MOSFET transistors Q4 and Q6 and the loads Rload1 - Rload4. These elements form the force circuit of the converter. One used two transistors in parallel with balancing resistors R1 and R5 in order to increase the output power. With switches S1 - S4 one can commute the loads Rload1 - Rload4 for testing the converter at load step variations. Loads obtained by operating the switches $\mathrm{S} 1-\mathrm{S} 4$ are $35 \Omega, 27 \Omega, 20 \Omega$ and $15 \Omega$. Component values are shown on the scheme. MOSFET command is realized by a command circuit with discrete components.

Command circuit contains two 555s and a comparator LM311. The first 555, A1, generates $10 \mathrm{kHz}$ pulses. Because MULTISIM works badly at very small duty cycles of the 555, one used the configuration for high duty cycles (about $85 \%$ ) and after that the transistor Q3 in inverting configuration. The second 555, A2, is used as linear variable voltage generator (LVV). Its output signal is not a pure linear variable voltage, but an exponential curve, specific to the loading process of a capacitor; with a corresponding adjustment is good enough to generate the PWM pulses for MOSFETs.

PWM pulses are generated by LM311 comparator. It compares the LVV with the voltage obtained from the P.I. (proportional-integrator) controller. The error signal is obtained by a differential amplifier with the operational U2, 741 type. It makes the difference between the reference given by the divider R24 and R25 and the voltage from the divider R22 and R23 which is proportional with the output voltage. This difference is applied to the P.I. controller implemented with the operational U3. (Multisim \& Electronics 2001), (National Instrumenrs Co. LabView). 


\section{Experimental development of the converter}

In figure 5 is the command circuit and in figure 6 is presented the force circuit of the prototype both in OrCAD. For reasons of PCB optimization, the force and the command circuits were placed on separate boards ( Orcad Software, 2005) .

In order to minimize the coils magnetic field influence upon the force transistors and other active components, they were placed separately on a third board and shielded. In the force circuit, the balancing resistances were increased to $0.7 \Omega$ to limit the start current peaks. Using this value of $0.7 \Omega$ in numerical simulations led to a poor numerical stability.

Resistances used as current transducers had a nominal value of $0.1 \Omega$ but their measured values are shown on the scheme. Signals necessary to the command circuit are sent in the outlet $\mathrm{J} 8$ and the command signals for the transistors are received in inlet J6.

In figure 5 is the command circuit. It is fed indirectly from the force circuit at a voltage of $24 \mathrm{~V} \mathrm{DC}$, by the outlet J9. Because the circuits 555 needs a maximum voltage of $15 \mathrm{~V}$ one realized a stabilizer with LM317 which drops the voltage from 24 $\mathrm{V}$ to $15 \mathrm{~V}$ stabilized and after that a second stage, also with LM317 which ensures a median voltage of $7.5 \mathrm{~V}$ necessary to the operational circuits of the P.I. controller and conditioning signals blocks. Pulses generator, inverting transistor and LVV generator are realized as it is shown in figure 4. Differential amplifier, P.I. controller and comparator are as shown in figure 4.

Figure 5 contains a protection block which was not implemented in MULTISIM. It contains two comparators, COMP2 and COMP3, which compare the corresponding signals from output voltage and output current with reference values prescribed from trimmers RV9 and RV10. Comparators output are "OR"-ed with a diodes circuit. Further, the protection block is similar to the one shown in (Dinca L et al., 2013). "OR"s output feeds the inputs R1 and S2 of the CD4043; the Q1 output lights a green LED which signals a normal functioning and further feeds one of the inputs of an "AND" gate from CD 4081. By this way, the pulses from the comparator COMP1 goes further to the MOSFETs command. Output Q1 also opens the protection MOSFET M3. When an abnormal condition appears, the "OR"s output resets the Q1 output, stops the command pulses to the M1 and M2 MOSFETs and blocks the protection transistor M3. The green LED is turned off. In the same time, the Q2 output is set and lights the red LED and opens the transistor T4. The latter discharge the capacitor $\mathrm{C} 1$ from the force circuit, removing a possible overvoltage condition. An over-current condition has to be removed by the operator verifying the output load. The entire converter reset is reached with the SWITCH 4. It sets the Q1 flip flop and resets Q2. If the over-current or overvoltage conditions hold, the flip flops will switch again and turn off the converter.

For the MOSFETs M1 and M2 command one used the transistor T3 in repeater configuration with a divider in emitter. By this way, the output pulses from the CD4081 
"AND" gate, with an amplitude of $15 \mathrm{~V}$, are dropped to $5 \mathrm{~V}$ and then sent to $\mathrm{M} 1$ and M2 gates. One observed a direct command of M1 and M2 from CD 4081 distort the pulses due to the MOSFETs internal capacities.

For the input current measurement one used a differential amplifier AO3 which amplifies the voltage from the R1 resistor in the force circuit. In order to fit the signal in the measurement domain one made an offset of the $\mathrm{AO} 3$ output with the $\mathrm{AO} 4$ adder.

Figures $7 \mathrm{a}, 7 \mathrm{~b}$ and $7 \mathrm{c}$ presents the coils board, force circuit board and command board respectively. In figure $7 \mathrm{~d}$ is shown the entire experimental system.

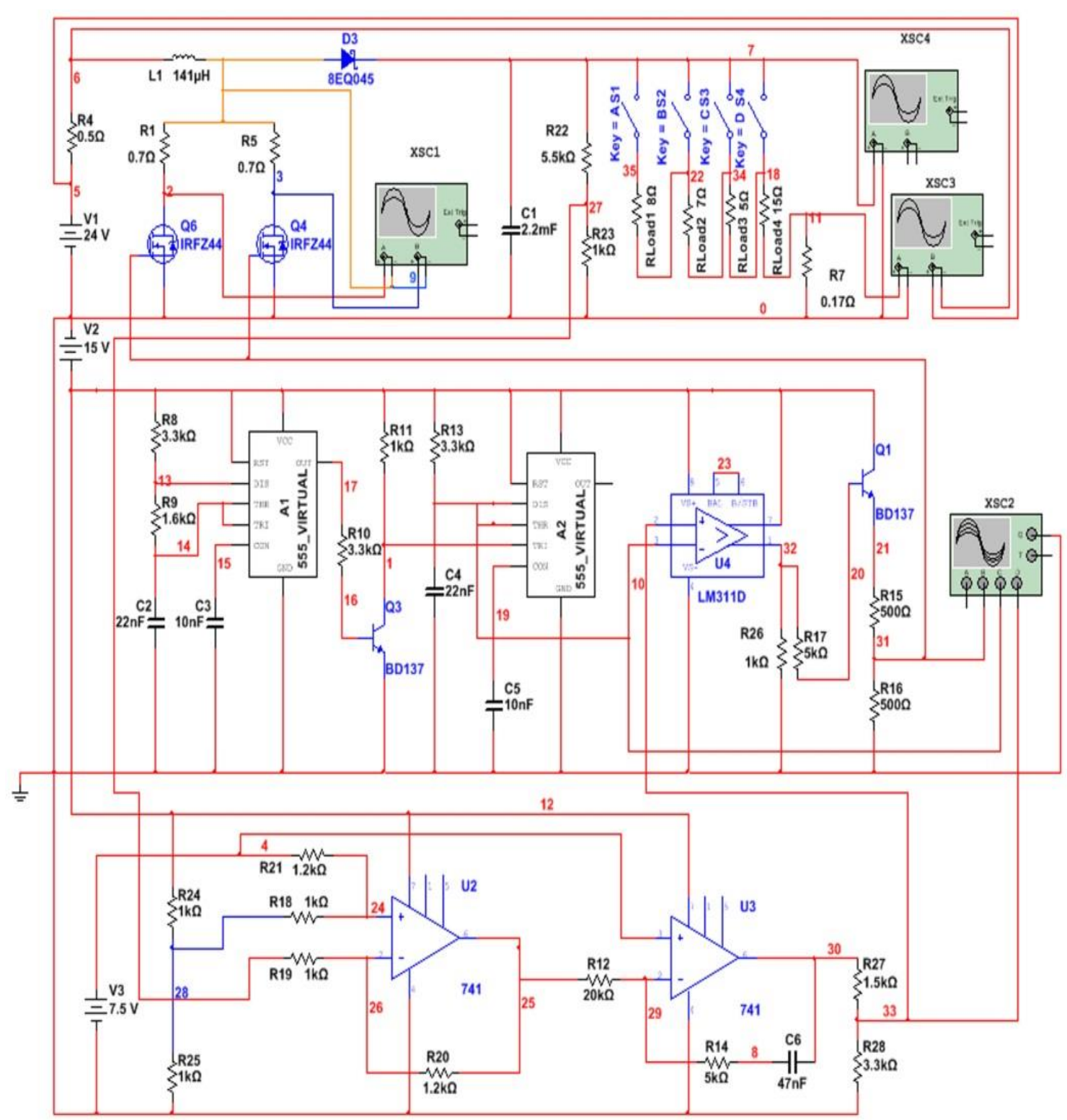

Fig. 4. Converter scheme in MULTISIM 
Corcau, J. I. \& Dinca, L.: Numerical Model and Experimental Tests for DC to DC ...

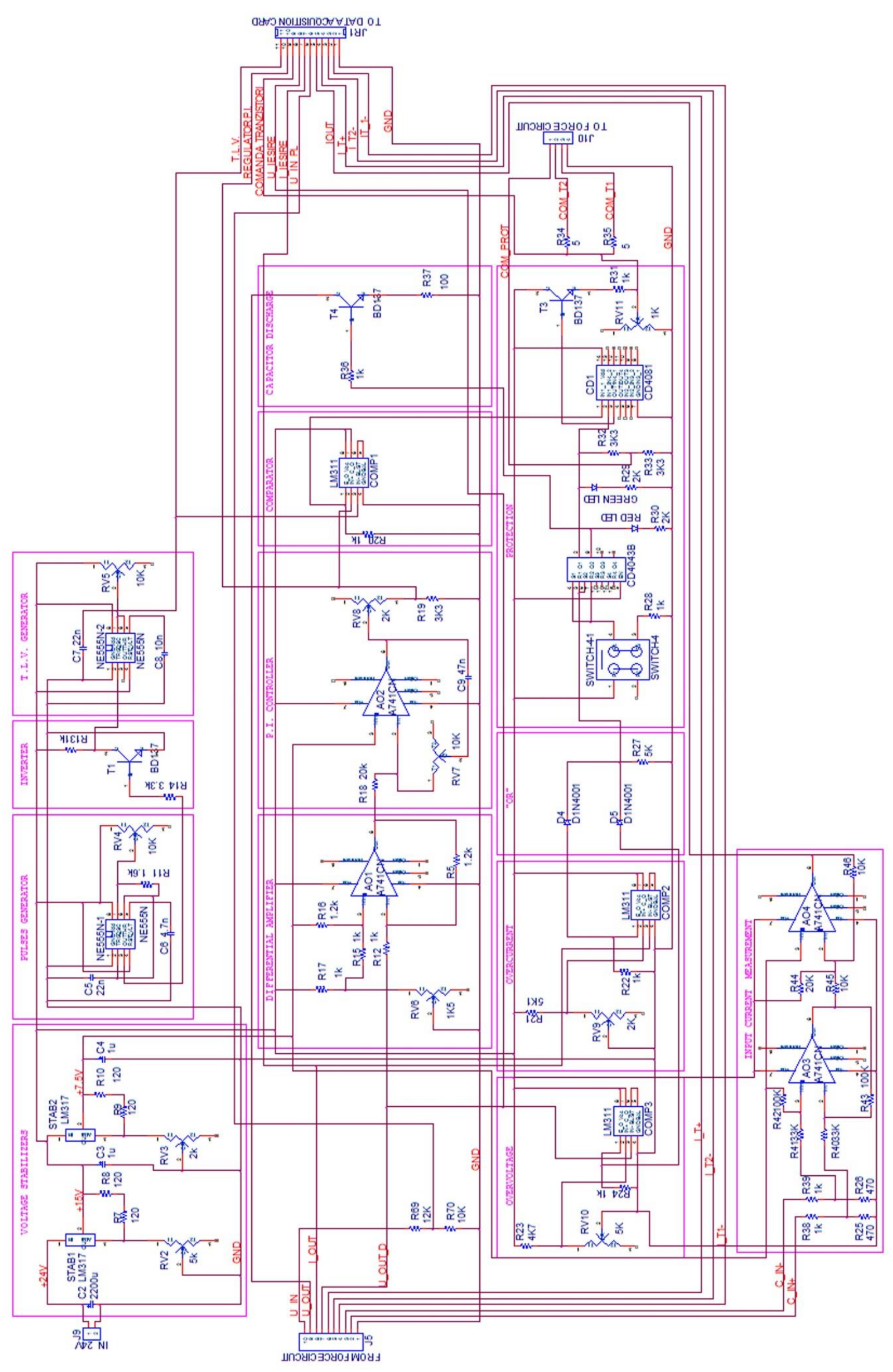

Fig. 5. Command circuit scheme 


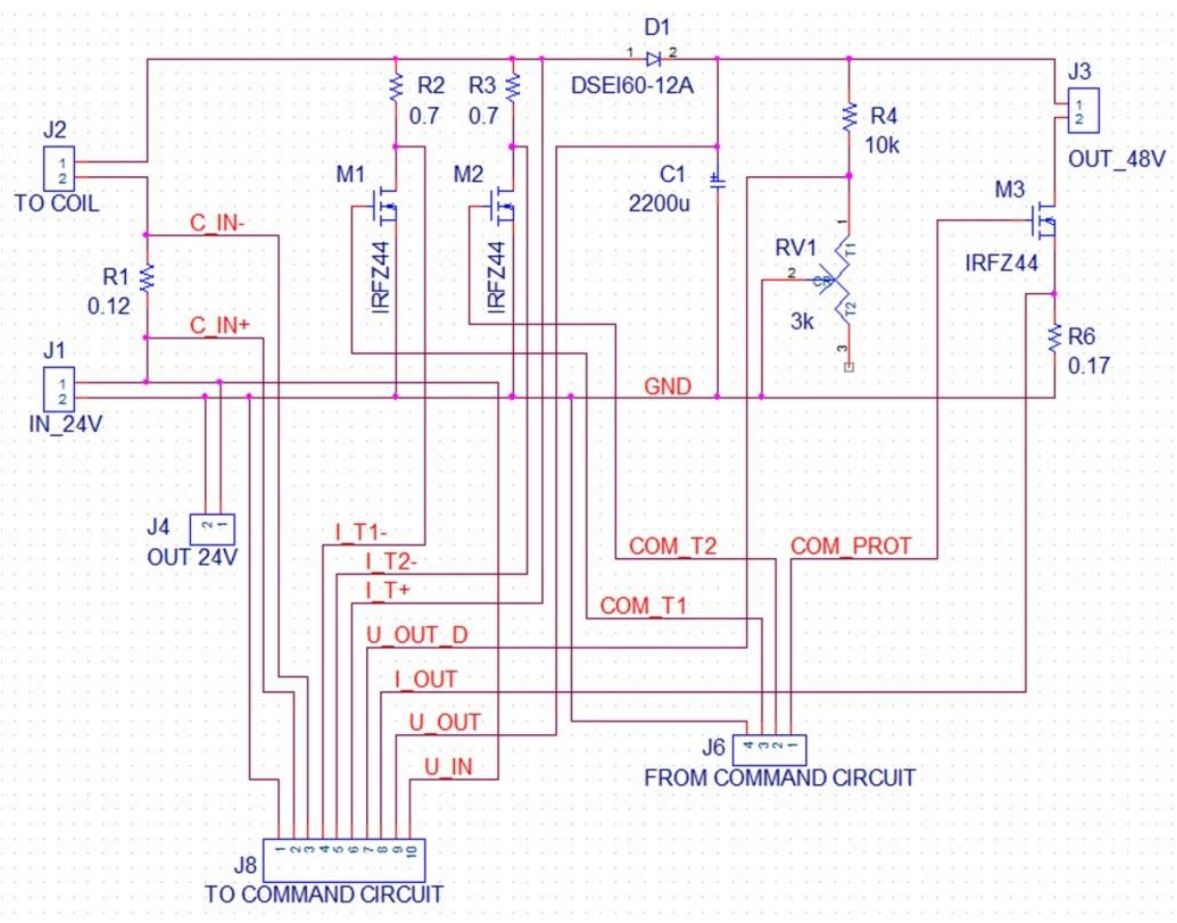

Fig. 6. Force circuit scheme

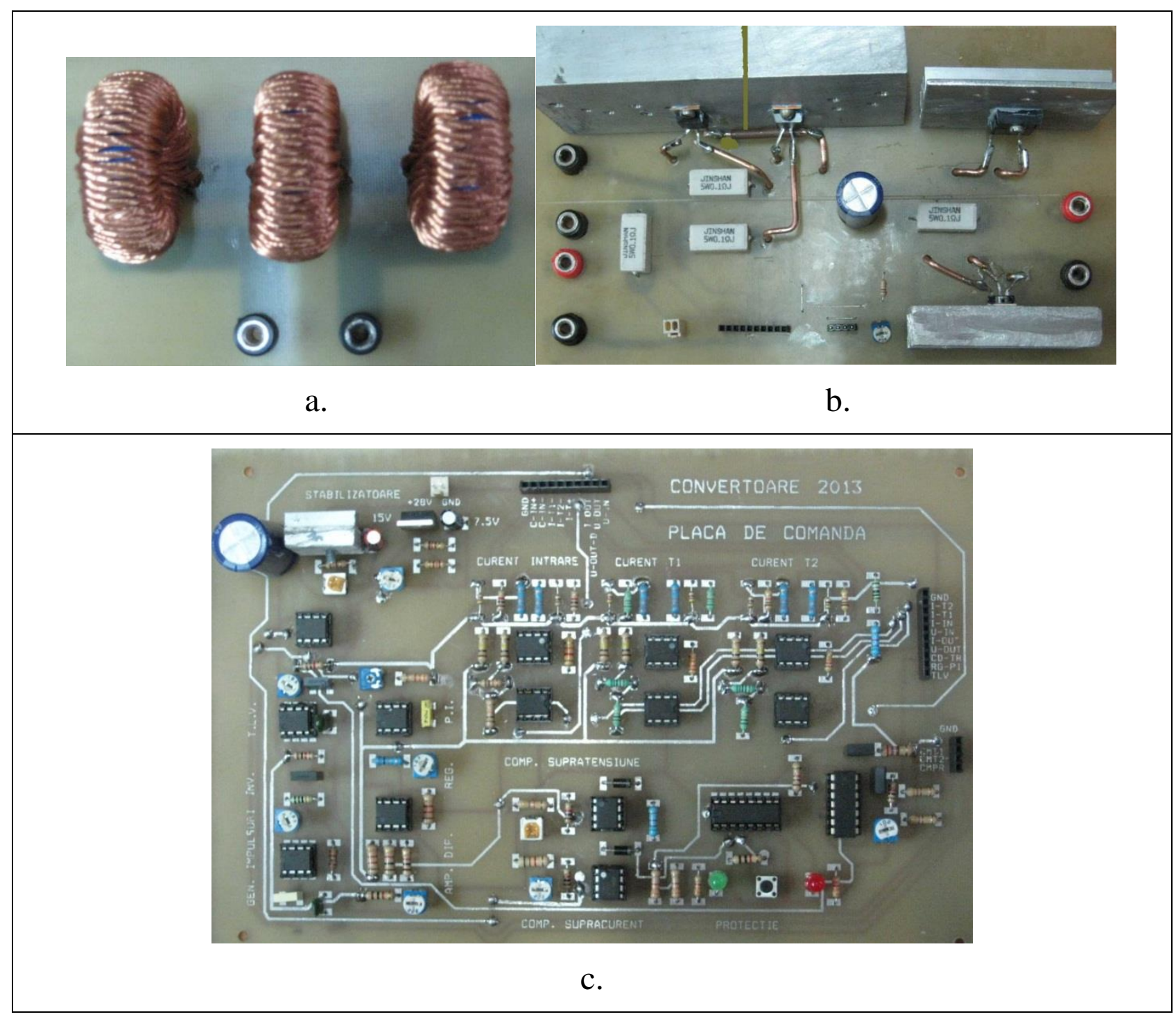




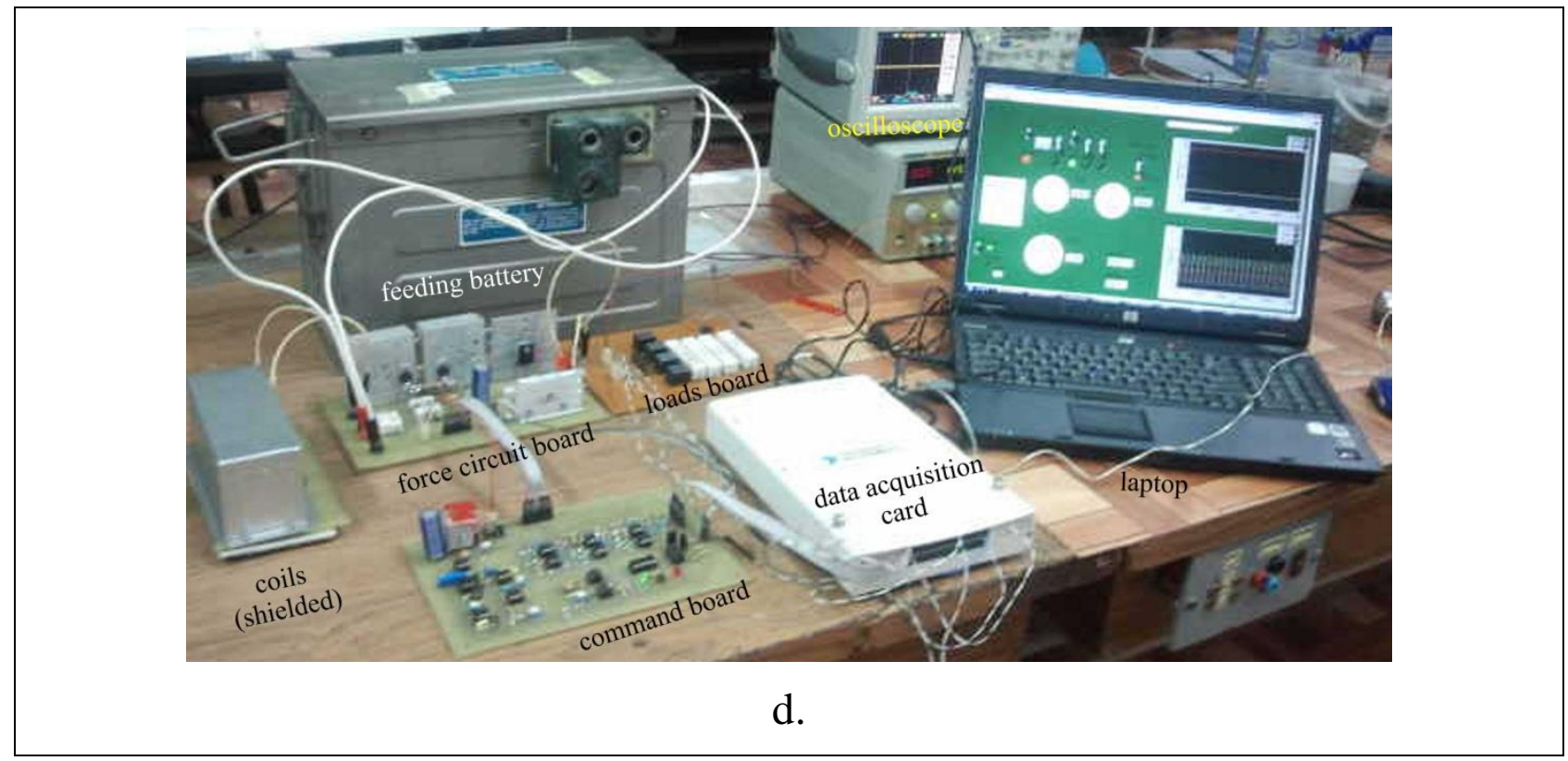

Fig. 7. Experimental system. a - coils board, b - force circuit board, c - command circuit board, $\mathrm{d}$ - overall system

\section{Data acquisition in Labview}

In figure 8 is presented the command panel for the scheme in LabView.

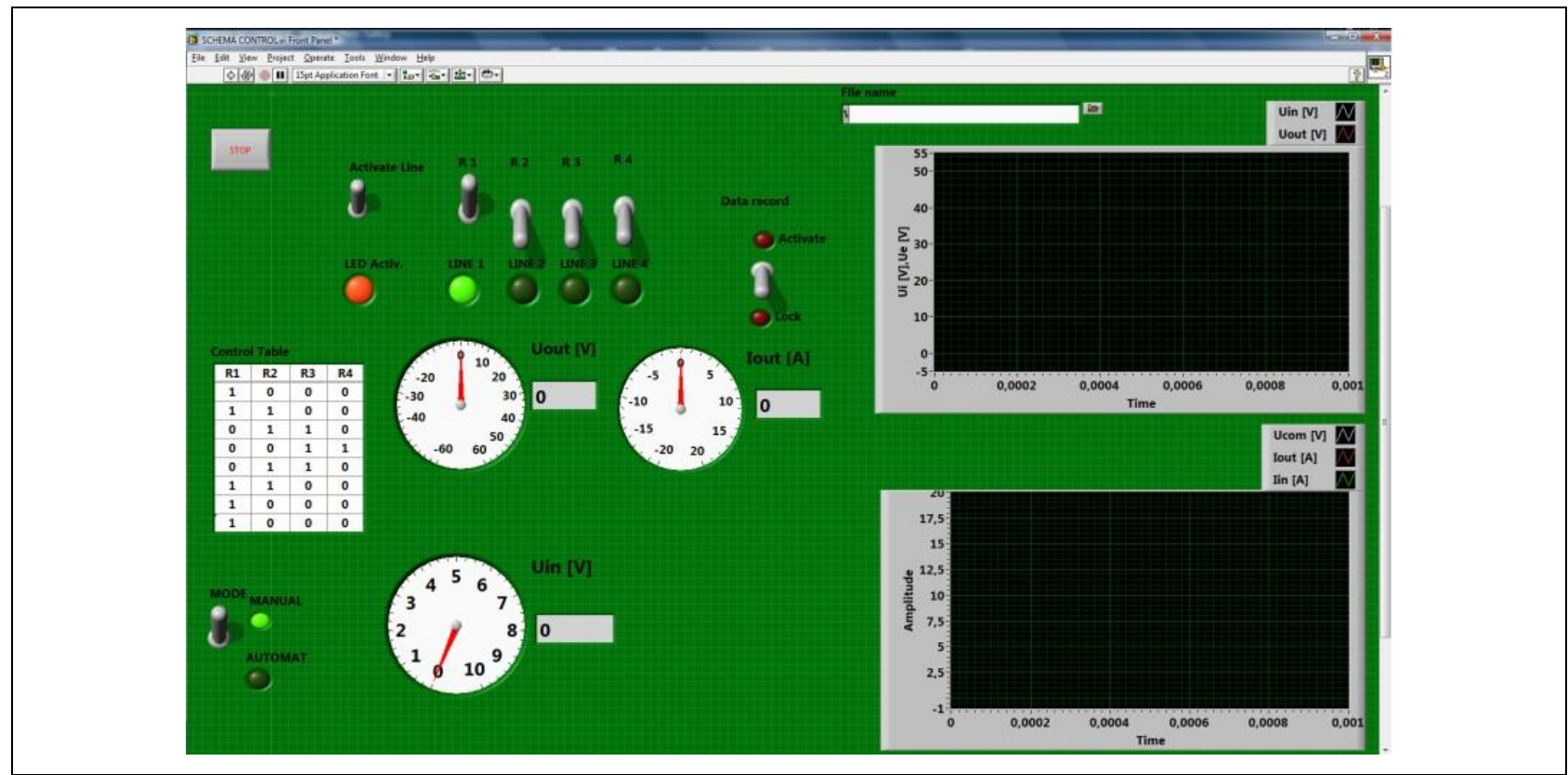

Fig. 8. Command panel

Acquisition scheme has the possibility cu acquire, visualize and record the following parameters: input voltage, input current, output voltage, output current and the command voltage applied on the MOSFETs gates. Moreover, it has the possibility to switch the loads, either in manual mode, either in automat mode. The loads switching 
is made by some relays, commanded by the digital outputs of the data acquisition board. This scheme is an adaptation after the scheme presented in (Corcau et al., 2013). The control scheme has three main sections: one for data acquisition and recording, the second for the manual switching of the loads and the third for the automat switching of the loads. In automat mode one can specify a sequence of eight steps in the table from the command panel.

Data acquisition card is a NI 6251 USB with a maximum sampling frequency of 1.2 Msample/s. One used a frequency of $350 \mathrm{Ksample/s/channel.}$

\section{Numerical and experimental results}

Using the simulation scheme in figure 4 one obtained the following variations of the converter parameters. Simulations were performed for two cases: load $35 \Omega$ and 15 $\Omega$. Figures $9 \mathrm{a}, 9 \mathrm{~b}, 9 \mathrm{c}, 9 \mathrm{~d}$ and $9 \mathrm{e}$ show the time variations, in the case of $35 \Omega$ load, for the following parameters: output voltage (fig. 9a), detail on output voltage (fig. 9b), input and output currents (fig. 9c), MOSFETs currents (fig. 9d) and the control system characteristic voltages (fig. 9e). For the currents visualization one presented the variation of the corresponding voltage on a resistor used as current transducer: for the input current the resistor is $R 4=0.5 \Omega$, for the output current the resistor is $R 7=0.17 \Omega$, and for the MOSFETs currents the resistors are R1=R5=0.1 $\Omega$. Figures 10a, 10b, 10c, $10 \mathrm{~d}$ and $10 \mathrm{e}$ show the same parameters for $15 \Omega$ load.

Fig. 9a shows the output voltage variation from the converter start till a stationary regime. One observes a slight overshoot but it is insignificant. The counterpart figure 10 a for $15 \Omega$ load reflects the canceling of the overshoot of the output voltage. Figures $9 \mathrm{~b}$ and respectively $10 \mathrm{~b}$ presents details of the output voltage in these situations. One observes the voltage ripple which have the characteristic aspect of a charge-discharge process for a capacitor. This ripple has an amplitude about $1 \%$ from the output voltage.

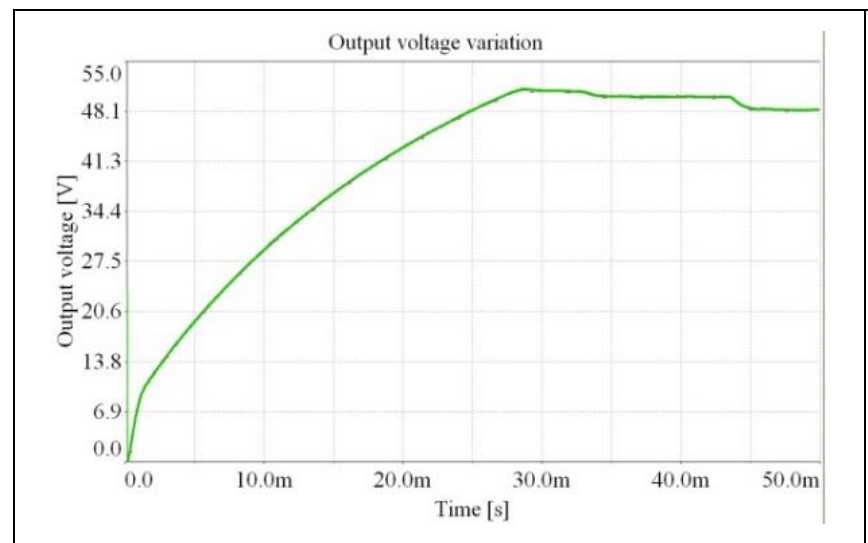

Fig. 9a. Output voltage on $35 \Omega$

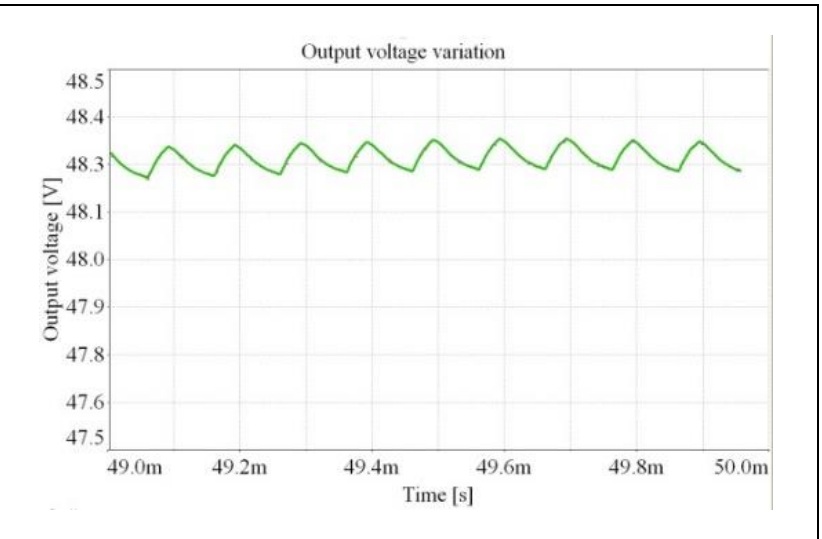

Fig. 9b. Output voltage on $35 \Omega-$ detail 
Corcau, J. I. \& Dinca, L.: Numerical Model and Experimental Tests for DC to DC
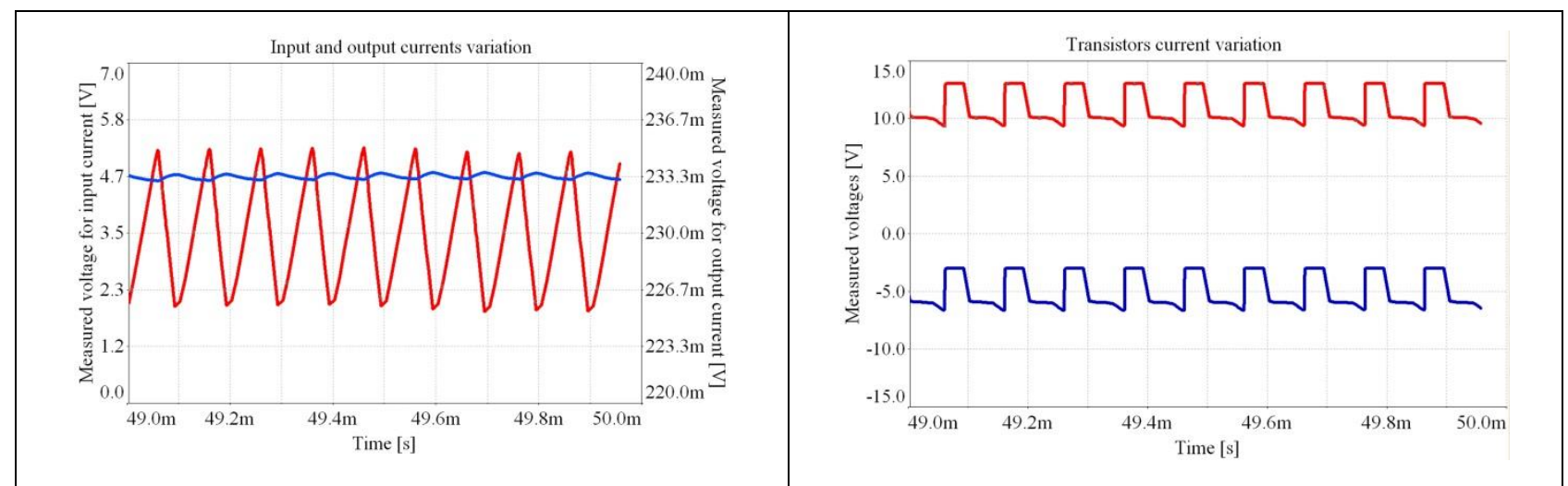

Fig. 9c Input and output currents on $35 \Omega \quad$ Fig. 9d MOSFETs currents - case $35 \Omega$ - detail load

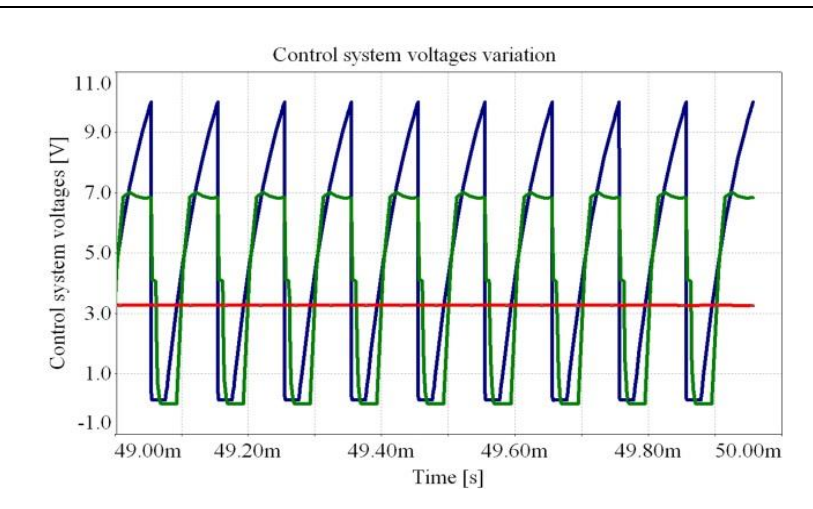

Fig. 9e. Characteristic voltages for the control system - case $35 \Omega$ load

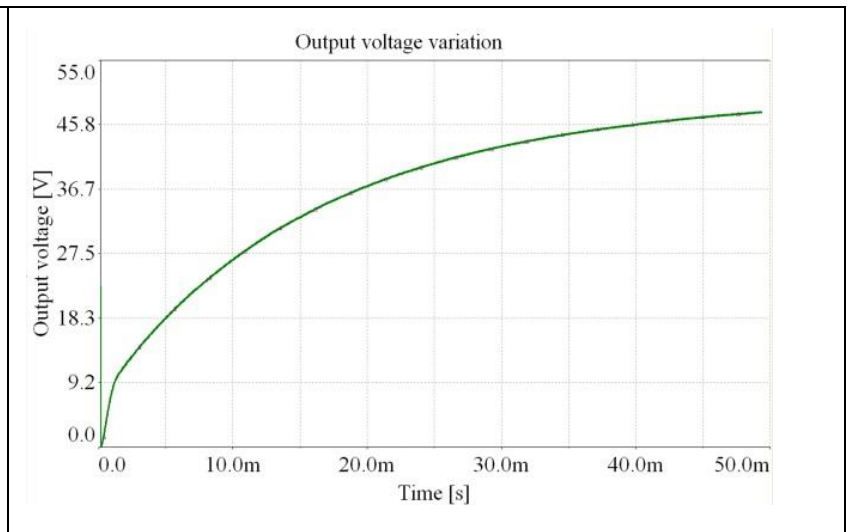

Fig. 10a Output voltage on $15 \Omega$

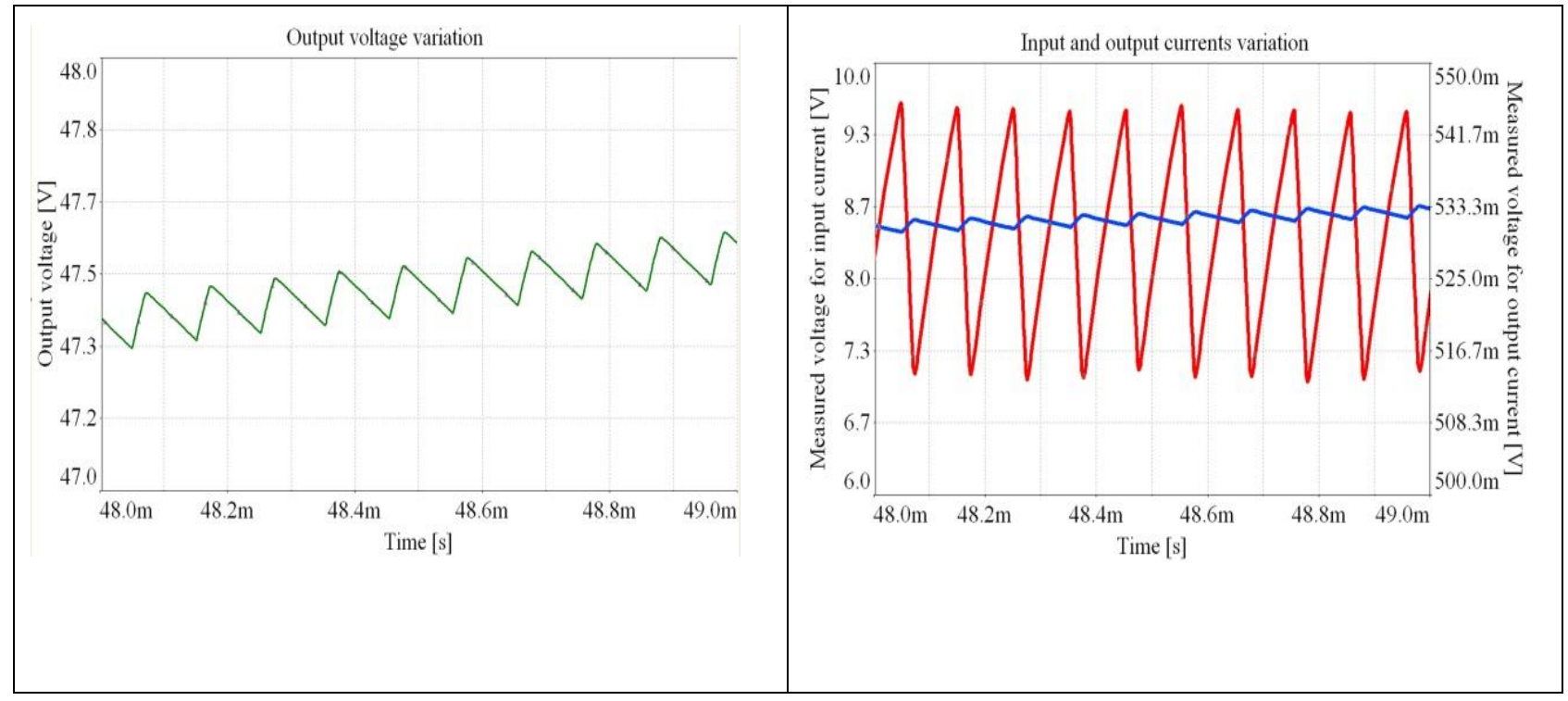

Fig. 10b Output voltage on $15 \Omega$ - detail

Fig. 10c Input and output currents on $15 \Omega$ 

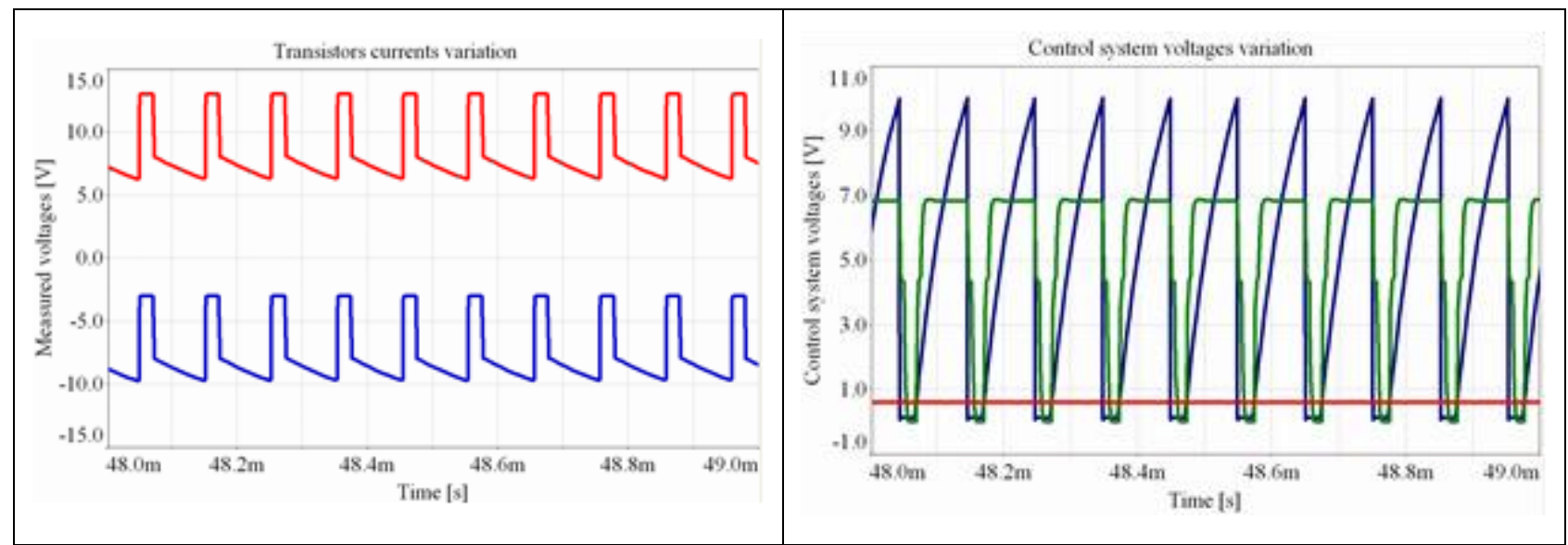

Fig. 10d. MOSFETs currents - case $15 \Omega$ Fig. 10e. Characteristic voltages for the load control system - case $15 \Omega$ load

Output and input currents of the converter are shown in figures $9 \mathrm{c}$ and respectively 10c, the ripple with a higher amplitude is for the input current.

The output current is in concordance with the output voltage, with ripple throughout $1 \%$. The waveform of the input current is in concordance with the theoretical aspects presented in literature and reflects the coil charge-discharge process. One notices the linear variation of the input current predicted by the theoretical studies.

MOSFETs currents are shown in figures $9 \mathrm{~d}$ and $10 \mathrm{~d}$. These variations present a quite important difference in relation to the theoretical studies. There are not linear variations like in theory but rather rectangular pulses, especially for the $35 \Omega$ load. Characteristic voltages for the control system, in figures $9 \mathrm{e}$ and $10 \mathrm{e}$, reflects it's functioning - MOSFETs switching when the LVV exceeds the P.I. controller voltage. The duty cycle of the command pulses increases with the load resistor decrease, but is larger than the theoretical and the experimental ones.

Figures 11-17 show the experimental results. Figure 11 is the calibration curve for the output current. Figure 12 is the output voltage variation. As feeding source one used an aviation battery with $24 \mathrm{~V}$ rated voltage and 36 Ah capacity.

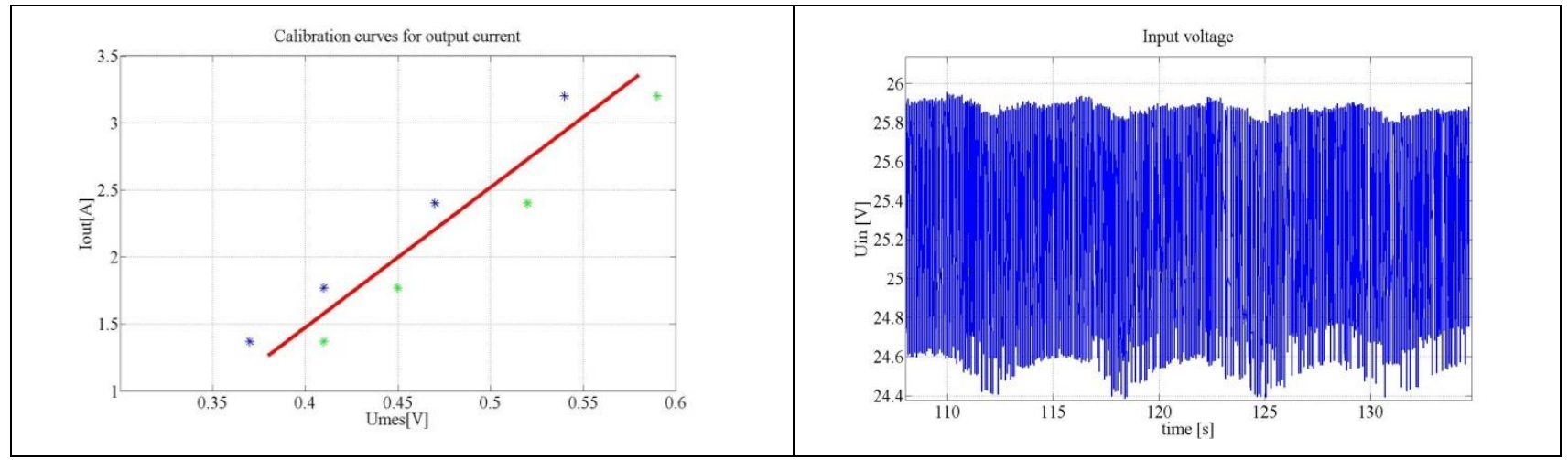

Fig. 11. Calibration curve for the output Fig. 12a. Input voltage current 


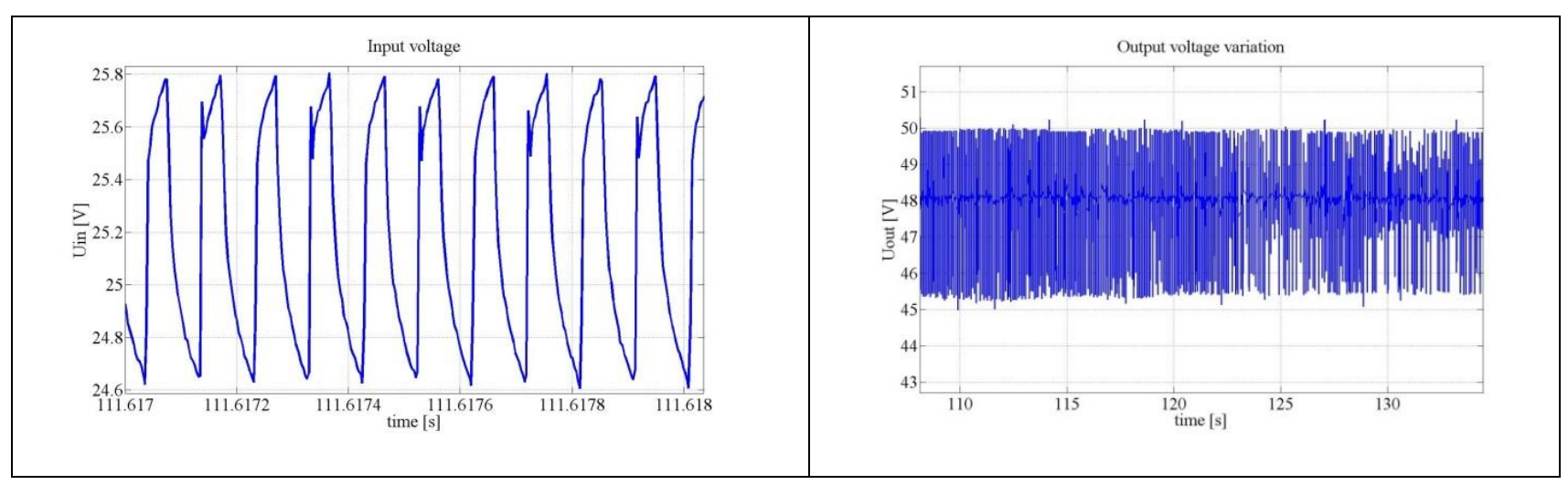

Fig. 12b. Input voltage - detail

Fig. 13a. Output voltage variation

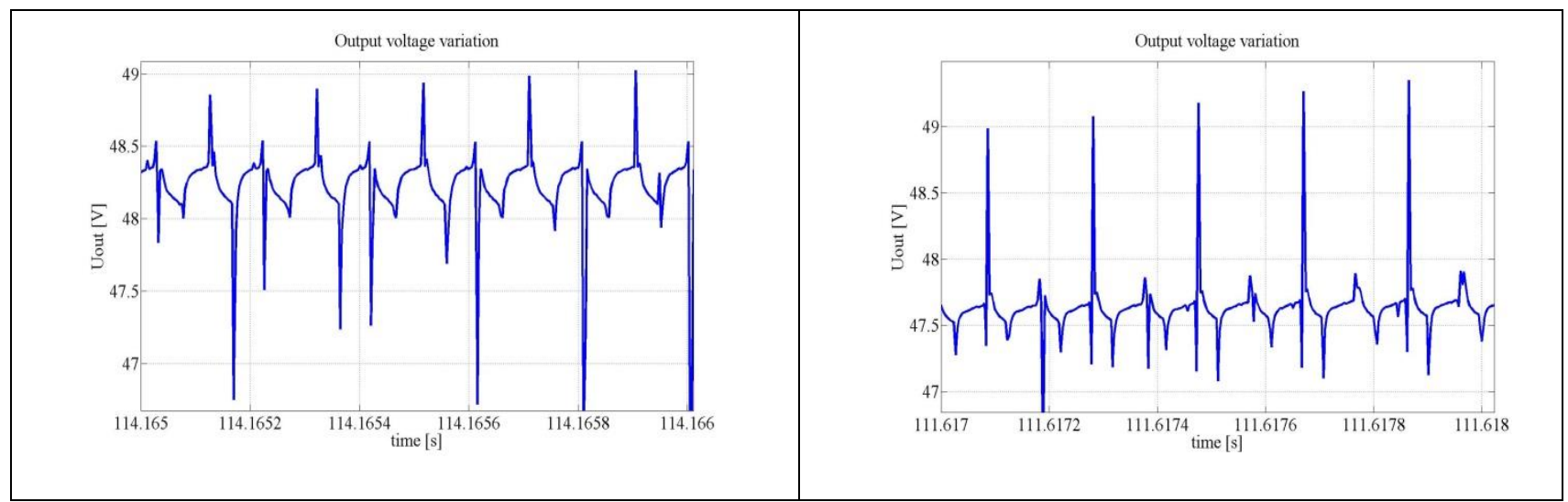

Fig. 13b. Output voltage - detail for $35 \Omega \quad$ Fig. 13c. Output voltage - detail for 15 load $\Omega$ load

Due to the internal resistance of the battery, the input current produces input voltage variations which are present both as average voltage variation and as ripple. However, one observes in figure $12 \mathrm{~b}$ the input voltage ripple is $1 \mathrm{~V}$ for $15 \Omega$ load. Beside the ripple due to the MOSFETs functioning one observe switching peaks. These peaks can be reduced with some RC circuits in parallel with the MOSFETs. Figures $13 \mathrm{a}, 13 \mathrm{~b}$ and $13 \mathrm{c}$ show the output voltage in time, for a larger period (fig. 13a) and details for $35 \Omega$ and $15 \Omega$ loads (fig. 13b, respectively fig. 13c).

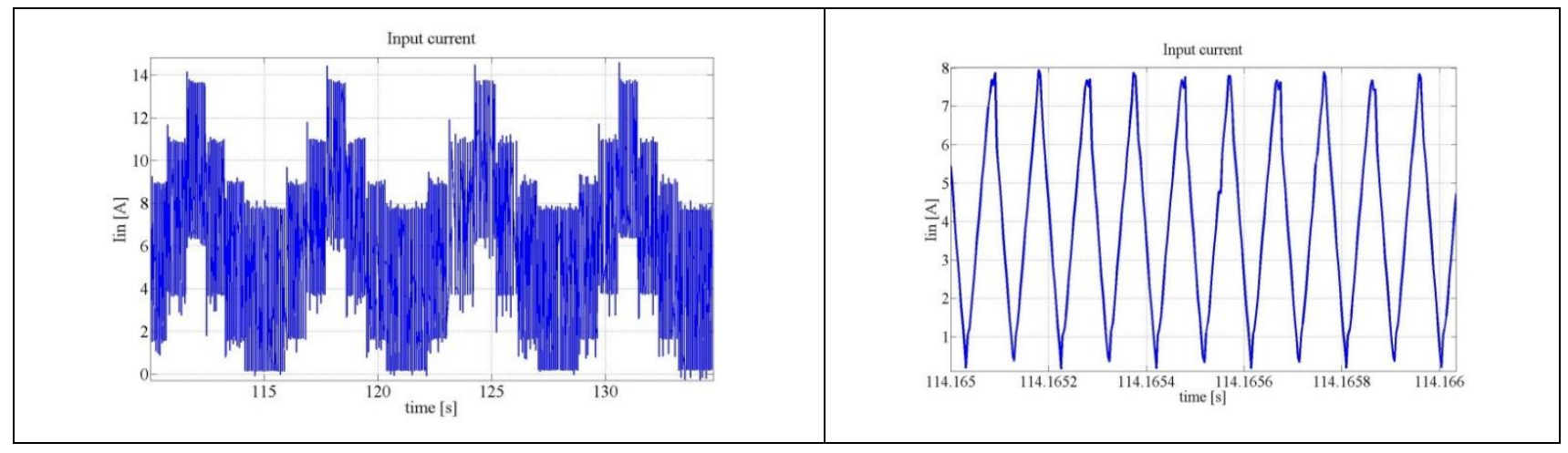

Fig. 14a. Input current variation

Fig. 14b. Input current - detail for 35 $\Omega$ load 


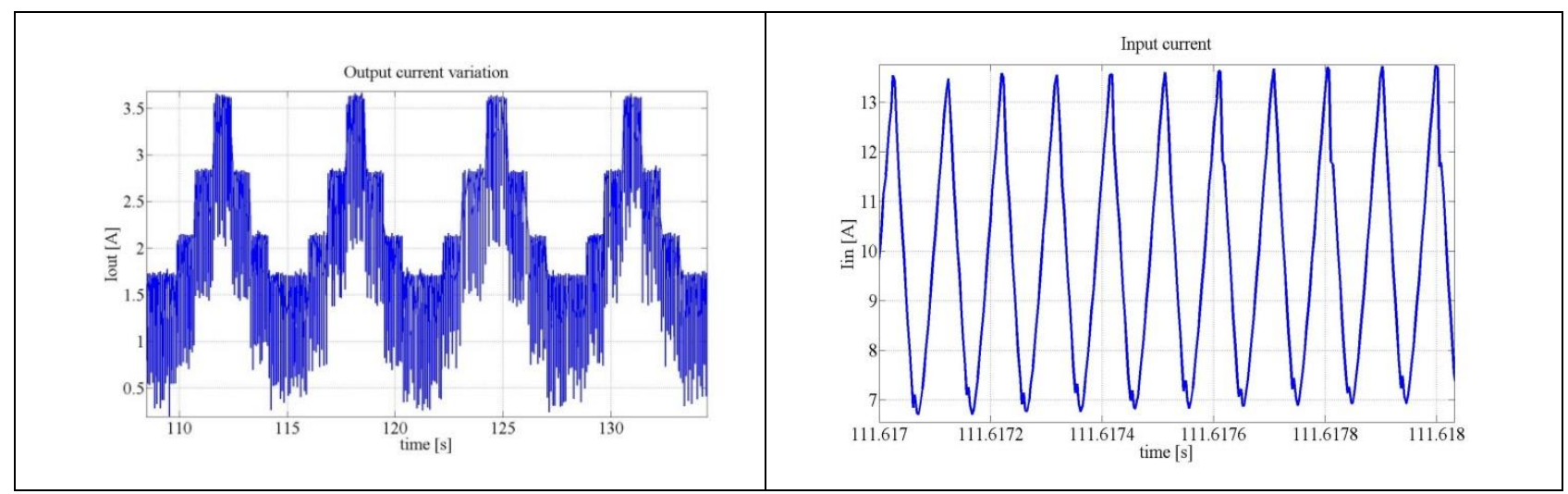

Fig. 14c. Input current - detail for $15 \Omega$ Fig. 15a. Output current variation load

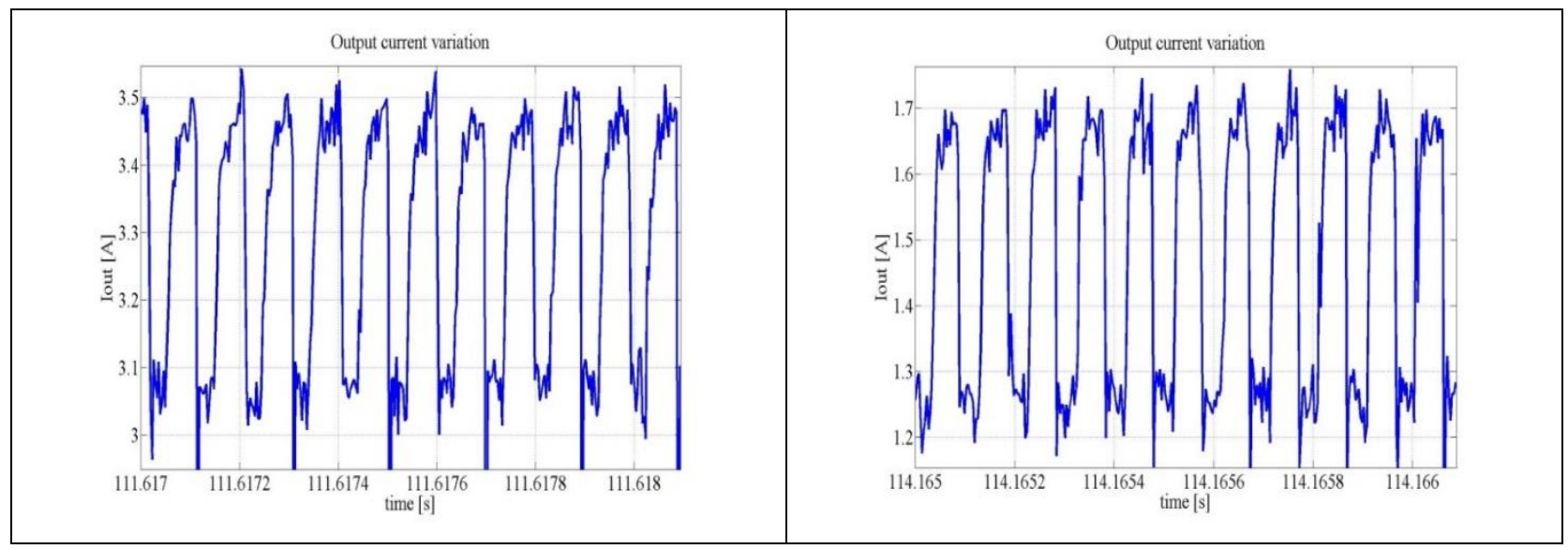

Fig. 15b. Output current - detail for $15 \Omega$ Fig. 15c. Output current - detail for 35 load $\Omega$ load

Output voltage has a average value about $48 \mathrm{~V}$, as it is stated in the design requirements, but it has two periodic components which may be improved in future. One of them is the capacitor charge-discharge process, put in evidence also in the numerical simulations in figures $9 \mathrm{~b}$ and $10 \mathrm{~b}$. One can say the experimental variation is closer an exponential than the numerical simulations, where the variations are rather linear for $15 \Omega$ load. The second components are the power devices switching peaks. These peaks are about $2 \mathrm{~V}$ and it is necessary to vanish them with the RC circuits specified above. These peaks have a wide harmonics domain and make the energy quality getting worse. In contrast, the capacitor charge-discharge ripple has a smaller amplitude and a narrower spectrum, so its influence on the energy quality is much smaller. Figure 14 presents the input current for a larger period (fig. 14a), with variations due to load variation obtained in automat mode switching and, details for 35 $\Omega$ load (fig. 14b) and respectively $15 \Omega$ load (fig. 14c).

As one can observe, these variations are in concordance with the simulation results in figure $9 \mathrm{c}$ and $10 \mathrm{c}$. The switching processes influence lesser the input currents. The experimental variations are almost perfectly linear, as it is stated in literature. Figure 15 presents the output current for a larger period (fig. 15a) and details 
for $35 \Omega$ load (fig. 15b) and respectively $15 \Omega$ load (fig. 15c). Output currents are distorted by the switching processes, as in the output voltage case. The waveform differs substantially from the numerical results. Using the experimental results one computed the converter efficiency using the relation

$$
\eta=\frac{\int_{t_{1}}^{t_{2}} U_{\text {out }} \cdot I_{\text {out }} \mathrm{d} t}{\int_{t_{1}}^{t_{2}} U_{\text {in }} \cdot I_{\text {in }} \mathrm{d} t}
$$

where $\left(t_{1}, t_{2}\right)$ was choose a multiple of the switching period. By this way one obtained a power mediation both to the output and to the input, so the result has a better precision. The obtained efficiency is about $66-70 \%$, depending on the output load.

\section{Conclusions and future works}

Boost converter designed and manufactured in the laboratory of aerospace engineering from the University of Craiova, satisfy the proposed requirements, but it can be improved to reduce the output voltage and current ripple. This improvement can be achieved using RC circuits in parallel with MOSFET switches and the power diode. Numerical model for the converter was performed in MULTISIM 12 and the simulation results are in a good concordance with the theoretical aspects in the literature and the experimental results. There are some differences concerning the MOSFETs current, but one can appreciate the entire simulation quite good, even for some values of the duty cycle and current transducer resistors appeared numerical instabilities. MULTISIM 12 proved to be a big help in the design process of the converter. Converter scheme was designed in order to fulfill the necessities of the didactical and research process, but with some improvements its application may be extended to industrial and aero-spatial domain. These converters are widely used on the MEA aircraft and also space vehicles, in electrical systems with fuel cells, photovoltaic panels and buffer batteries.

Boost converter presented in this work can be improved, besides the switching peaks canceling devices, in some important directions, such a command system based on a microcontroller, which permits implementation of better control laws than the PI one used in this paper, and also more complex protections. Another advantage of this direction is decrease of size and weight for the control board and by the way for the entire converter. Another development direction which is growing worldwide is the interleaved phases converter which permit a significant decrease of the input current ripples (Bizon N., et al., 2006), (Choe G. Y., et al., 2010), (Shin H.B., et al., 2005). This aspect is very important for the fuel cell systems which do not permit high amplitude and frequency current ripples. Such converters can be designed also with digital control which simplifies the entire converter scheme. 


\section{References}

Rashid, M. H. (2003) Power Electronics Circuits, Devices, And Applications, 3rd edition, University of West Florida, Pearson Prentice Hall

Chellappan, M.V. Fuel cell based battery-less UPS system. Master of Science, August 2008, available online

Marsala, G. (2008). Modeling and implementation of an emulator for fuel cell systems development of control strategies and laws. Ecole doctorale SPIM"Sciences pour l'ingenieur et microtechniques" These

Fadali, H. (2008) Fuel cell distributed generation: Power Conditioning, Control and Energy Management, $\mathrm{PhD}$ theisis

Misoc, F. (2007) A comparative study of $d c-d c$ converters effects on the output characteristic of direct ethanol fuel cells and NI-Cd Batteries. Master of Sciences, Kansas State University

Biswal, M. \& Sabyasachi, S. (2012) A Study on Recent DC-DC Converters. International Journal of Engineering Research and Applications (IJERA), ISSN: 2248-9622, Vol. 2, Issue 6, pp.657-663

Sathya, P. \& Natarajan, R. (2013) Design and Implementation of 12V/24V Closed loop Boost Converter for Solar Powered LED Lighting System. International Journal of Engineering and Technology (IJET), ISSN 0975-4024, pp. 254-264

Kabalo, M.; Paire, D.; Blunier, B.; Bouquain, D.; Simões, M. \& Miraoui, A. (2012) Experimental evaluation of four-phase floating interleaved boost converter design and control for fuel cell applications, IET Power Electron., pp. 1-12, ISSN 1755-4535

Sangswang, A. \& Nwankpa, C. O. ( 2004). Noise characteristics of DC-DC Boost Converters: Experimental Validation and Performance Evaluation. IEEE transactions on industrial electronics, Vol. 51, NO. 6, pp. 1297- 1304

Johansson, B. (2004) DC-DC Converters - Dynamic Model Design and Experimental Verification. Doctoral Dissertation, Lund, ISBN 91-88934-34-9

Bizon, N.; Sofron, E. \& Oproescu, M. (2006) An Investigations into the Fast- and Slow -Scale Instabilities of an Energy Generation System with a Fuzzy Hysteretic Control. Advances in Intelligent Systems and Technologies Proceedings ECIT, Romania, pp. 1-16

Livinti, P. T. \& Stoleru, A. (2011). Computerized Control and Monitoring of an Electric Driving System, Annals of DAAAM for 2011 \& Proceedings of the 22nd International DAAAM Symposium, 23-26th November 2011, Vienna, Austria, Volume 22, No. 1, ISSN 1726-9679, ISBN 978-3-901509-83-4, Katalinic, B. (Ed.), pp. 0317-0318, Published by DAAAM International Vienna

Osmanaj, S.; Xhuvani, A.; Limani, M. \& Selimaj, R. (2009). Analysis of PWM Voltage Source Inverters in the Overmodulation Region, Annals of DAAAM for 2009 \& Proceedings of the 20th International DAAAM Symposium, 25-28th November 2009, Vienna, Austria, ISSN 1726-9679, ISBN 978-3-901509-70-4, Katalinic, B. (Ed.), pp. 0007-0008, Published by DAAAM International Vienna 
Baluta, G. \& Coteata, M. (2009). Period-to-Voltage Converter, Annals of DAAAM for 2009 \& Proceedings of the 20th International DAAAM Symposium, 25-28th November 2009, Vienna, Austria, ISSN 1726-9679, ISBN 978-3-901509-70-4, Katalinic, B. (Ed.), pp. 0001-0002, Published by DAAAM International Vienna Seyezhai,R.; Abhineya, V.; Aishwarya, M. \& Gayathri, K. (2013) Hardware implementation of two-phase bridgeless interleaved boost converter for power factor correction. Journal of Science and Technology, ISSN 0799-3757, SciTech,Vol.1,194202

Liu, J.; Wong, K. L.; Allen, S. \& Mookken, J. Performance Evaluations of HardSwitching Interleaved DC/DC Boost Converter with New Generation Silicon Carbide MOSFETs. Available online

Hemachander, P.; VimalRaj, A. D. \& Sudhakaran, M. (2011) Analysis Design and Implementation of Soft Single Switched Boost Converter. International Journal of Computer Applications (0975 - 8887),Volume 26, No.11, pp. 38-46

Priambodo, P. S.; Sukoco, D.; Purnomo, W.; Sudibyo, H. \& Hartanto, D. (2013). Electric Energy Management and Engineering in Solar Cell System. Chapter 12, INTECH, pp. 327-351

Dinca, L.; Corcau, J.; Grigorie, T.L. \& Tudosie, A. (2013) Considerations concerning modeling, analysis and design of a dc-dc boost converter using Multisim. Proceedings of the 1st International Conference on Aeronautical and Mechanical Engineering, Greece, ISSN: 2227-4596, ISBN: 978-1-61804-185-2; pp. 201-206

Corcau, J.; Dinca, L. \& Grigorie, T.L. (2013). Automatic control of a boost dc-dc converter. 13th International Multidisciplinary Scientific GeoConference \& EXPO Bulgaria, ISBN 978-619-7105-06-3; ISSN 1314-2704; pp. 585-592

Corcau, J.; Dinca, L. \& Grigorie, T.L. (2013). Computerised tester for monitoring inverters dynamic behavior. 1 th International Conference New Challenges in Aerospace Sciences NCAS; pp. 5-9, Romania, ISSN 2344-4762

Amala, A.; Parameshwari, P. \& Pallavi, P (2011). Quasi resonant ZVS boost converter. Gokaraju Rangaraju Institute of Engineering \& Technology Bachupally;

Choe, G.Y.; Kim, J. S.; Kang, H. S.\& Lee, B. L. (2010) An Optimal Design Methodology of an Interleaved Boost Converter for Fuel Cell Applications. Journal of Electrical Engineering \& Technology Vol. 5, No. 2, pp. 319 328

****Multisim \& Electronics Worktech (TM), user manual, 2001

*** Orcad Cypress Software Inc., user manuals

***Graphical System Design Guide to Power Electronics Co-Simulation with Multisim and LabVIEW

*** National Instrumenrs Co. LabView User manual, www.ni.com/manuals ***NI USB6251, user manual, www.ni.com/manual 